\title{
Modos de pensamentos reflexivos implícitos nos fatores de aperfeiçoamento da prática musical
}

\author{
Regina Antunes Teixeira dos Santos* \\ Universidade Federal do Rio Grande do Sul
}

\section{Resumo:}

Pesquisas em prática instrumental apontam como fatores potenciais para garantir um aperfeiçoamento das condições de preparação de uma dada obra: (i) concentração; (ii) delimitação de metas exeqüíveis; (iii) constante auto-avaliação; (iv) estabelecimento de estratégias flexíveis; (v) visualização de um plano global. Os conceitos de reflexão, reflexividade e prática reflexiva, bem como suas conexões com modos de pensamento reflexivo podem ser subentendidos nesses fatores apontados em pesquisas sobre prática instrumental. Aspectos como experimentação da situação, ceticismo reflexivo, reflexão-sobre-a-ação e imaginação-em-ação são alguns dos pontos discutidos em conexão com a prática instrumental. A reflexividade, entendida como conversação intersubjetiva com a situação, parece não estar sendo levada em conta nas pesquisas em prática instrumental.

Palavras-chave: prática reflexiva; prática instrumental; pensamento reflexivo

\footnotetext{
* Regina Antunes Teixeira dos Santos graduou-se em Bacharelado em Piano, na UFRGS, tendo, posteriormente, realizado cursos de especialização junto a Université Toulouse Le Mirail (Toulouse, França) e Universidade Ueno Gakkuen (Tóquio, Japão). Em 2007 concluiu doutorado sob orientação da Profa ${ }^{a}$. Dra . Liane Hentschke junto ao Programa de Pós-Graduação em Música da UFRGS. Em pesquisa, sua área de interesse concentra-se na interconexão entre prática instrumental e conhecimento musical.
} 


\section{Introdução}

O termo prática reflexiva tem sido empregado em vários contextos, sob a ótica de diferentes domínios, para referir-se a formas diferenciadas de pensamentos e de geração de conhecimentos em uma dada profissão, às maneiras de ensinar e aprender, à qualidade de produtos (na prática e sobre a prática), em termos de atividade individual ou coletiva, bem como suas implicações no desenvolvimento e transformação do conhecimento pessoal frente a uma dada área. Por um lado, pode-se considerá-la como uma forma de (auto-) avaliação e autoconhecimento que facilitam a compreensão das zonas de conforto e dificuldades da prática de um indivíduo. Por outro lado, ela representa um processo dinâmico, deliberado e sistemático de avançar o desenvolvimento pessoal e profissional. Exemplos de pesquisas recentes em prática reflexiva podem ser encontrados em áreas, tais como, educação, ciências da saúde, sociologia, antropologia e administração, entre outras. ${ }^{1}$

Especificamente em Música, situações de prática e de pensamentos reflexivos têm sido investigadas em contextos tais como: ensino de instrumento 114 para estudantes de nível médio (Reynolds; Beitler 2007); prática de ensino de estagiários de música (Reynolds et al., 2006); situações de resolução de problemas como fator alavancador de habilidades cognitivas nos estudantes de pós-graduação em educação musical (Otacioglu, 2007); prática reflexiva associada à criatividade em atividades de composição, performance e improvisação de estudantes em música (Collins, 2007; Reid; Petocz, 2004. McAdams, 2004; Wiggins, 1999). Com relação à prática de um instrumento, apesar das pesquisas não relacionarem diretamente o pensamento reflexivo aí contido, pode-se interpretar muitas das situações descritas nessas pesquisas como modos de pensamento reflexivo. O presente artigo visa apresentar fatores

1 As referências nestas áreas são as seguintes: educação: Tan (2008), Towndrow (2008); ciências da saúde: Mamede et al. (2008), Andersón et al. (2007), Cronin e Connolly (2007); sociologia: Hughes e Heycox (2008), Mishna e Bogo (2007), Ruch (2007); antropologia: Jacob (1995); administração: Small e Cullen (1995), Smith (2001), Lee (2003). 
apontados na literatura como propulsores para o aperfeiçoamento da prática instrumental, analisados sob a perspectiva de modos de pensamento reflexivo. Inicialmente, esse texto apresenta uma breve revisão dos conceitos de reflexão, reflexividade e prática reflexiva, sua conexão com a perspectiva crítica de pensamento e finalmente, uma interpretação desses aspectos nos fatores apontados nas pesquisas em prática instrumental.

\section{Conceitos de reflexão, reflexividade e prática reflexiva}

Por volta de 1930, Dewey definiu reflexão no contexto da prática como um processo de experimentação e avaliação contínua de crenças, afirmações e hipóteses, suas origens e seus impactos. Essa vertente epistemológica, de natureza pragmática, contém afinidades com várias correntes filosóficas e pedagógicas. O construtivismo, por exemplo, desfrutou uma relação íntima com esse modo de pensar, ao considerar que o aprendiz reflete sobre seu conhecimento e experiências atuais e passadas para gerar novas idéias e conceitos. A aprendizagem é entendida como um processo ativo, mantendo certo ceticismo sobre a possibilidade de se chegar a uma verdade objetiva como objeto do conhecimento. O elemento humanístico da prática reflexiva é sua preocupação com o crescimento pessoal e com o desprendimento frente a valores que possam limitar esse crescimento (Kullman, 1998).

Para Brookfield (1995), a pedagogia crítica, acoplando o exame das bases de poder subjacentes e o esforço, e o pragmatismo americano, enfatizando a implementação, a testagem e o refinamento das idéias através da experiência, acabaram moldando os conceitos de prática reflexiva Na perspectiva pragmática, o binômio prática reflexiva e resolução de problemas encontra-se freqüentemente associado. Para Dewey (1938), o pensamento reflexivo é acionado por situações problemáticas, onde a perspectiva crítica ocorre através dos julgamentos efetuados no processo de seleção sobre o quê observar e como solucionar problemas. Para Dewey, pensamento reflexivo envolve, num primeiro momento, um estado de dúvida, hesitação na qual se originam pensamentos destinados à 
solução de problemas. Para McPeck (1981), dentro da perspectiva da pedagogia crítica, o contexto problemático deve envolver postura critica em temos de ceticismo reflexivo com vistas inicialmente a uma abertura sobre possibilidades do contexto em questão. Assim, se para Dewey o aspecto temporal se dilata no processo de pensamento reflexivo, que, por sua vez, alavanca a possibilidade de julgamentos sobre possíveis hipóteses surgidas a partir de situações problemáticas, para McPeck é o próprio pensamento crítico que dilata o tempo dentro de uma perspectiva de ceticismo reflexivo. Para este autor, direcionar o olhar para a situação problemática exige uma postura de abertura reflexiva sobre os potenciais limites e armadilhas aos quais, muitas vezes, nosso processo de pensamento está habituado.

Reflexão pode ser compreendida como modos de pensar direcionados à exploração e à problematização de situações que freqüentemente nos conduzem a descobertas e resultados inesperados. No sentido físico do termo pode-se pensar em espelhos e imagens refletidas, que implicam versões paralelas do mundo. Biggs (1999) enfatiza a analogia entre a reflexão especular e esta no contexto da prática. A reflexão em um espelho é a réplica exata daquilo que está a sua frente. A reflexão na prática profissional, contudo, não fornece aquilo que é, mas aquilo que deveria ser: um aperfeiçoamento, uma melhoria do original.

Todos nós reconhecemos a importância da atividade de reflexão em nossas situações de prática, pois precisamos de tempo para compreender e conferir sentido pessoal àquilo que embora experienciado, não tenha sido suficientemente assimilado. O termo reflexão pode também estar relacionado a grupos de pessoas ativamente engajadas na discussão, na meditação e no questionamento de determinados tópicos ou eventos de interesse comum. Segundo Darling (1998), o conceito de reflexividade refere-se aos pensamentos surgidos a partir da interação com os outros, podendo atuar como um meio que influencia pensamentos reflexivos. Em outras palavras, na reflexividade, o sujeito está focado em comunicar suas intenções e compreender a perspectiva do(s) outro(s), podendo assim, de alguma forma, se conscientizar e questionar sobre suas próprias afirmações, pressuposições e prioridades. Em analogia à proposição 
de reflexão especular de Biggs, pode-se vislumbrar, na situação de reflexividade, outro modo de pensamento que implica a reflexão, dita difusa, que ao contrário da especular, se dispersa em várias direções. Nesse sentido, a noção de modos de pensamentos divergentes associados à criatividade (Amabile, 1996; Coon, 1989; Baroni, 2006) sugere uma relação entre modos de pensamentos reflexivos (divergentes) e atividade criativa.

Reflexão implica uma conexão ao contexto temporal na qual essa ocorre. Fala-se na existência de um tempo reflexivo (Burnard, 2006, p. 3-6), na qual nos engajamos em modos de pensamentos direcionados e focados em dimensões distintas. George e Yates (2002) enfatizam essa questão temporal da reflexão, ao assumir que o conhecimento pessoal move-se de estágios pré-reflexivos, para quase-reflexivos até atingir estágios reflexivos. A adoção desses estágios configura-se como uma forma de caracterização do fenômeno de aperfeiçoamento e de poder de concentração do pensamento humano frente a um dado contexto a ser questionado e problematizado.

O estágio pré-reflexivo manifesta-se tanto por meio de uma maneira tácita de conhecer (ações e pensamentos hábeis) como nos momentos em que estamos nos voltando e focando para uma situação que queremos, de alguma forma, desvendar. No segundo estágio, quase-reflexivo, os pensamentos (convergentes e divergentes) estão ocorrendo ao curso da própria ação. Nessa situação são lançadas e testadas hipóteses, afirmações e pressuposições. Esse estágio quase-reflexivo pode estar associado àquilo que certos autores (Hentshke; Del Ben, 2006; Hilton, 2006) denominam de conversação reflexiva com a situação, pois nesse sentido há uma busca para se encontrar e construir ativamente um significado pessoal em uma dada situação. No terceiro estágio, a situação contextual apresenta-se como uma experiência acumulada e o espectro de pensamentos reflexivos que iluminaram as facilidades e dificuldades encontradas no contexto proporcionam ao sujeito uma situação de aprendizagem. Um contexto de prática reflexiva pode assim implicar em mudança de perspectiva à medida que pode acarretar redirecionamento, tendo em vista a interdependência entre pensamento e ação voltados à solução de problemas 
contextuais. Nessa perspectiva, o foco parece estar no pensamento humano frente às situações de prática, e não no poder incondicional da situação de prática.

Para Schön $(1983,1987)$, reflexão está intimamente ligada às situações de delineamento e desenvolvimento de um projeto, onde pensamentos e ações reflexivas ocorrem em diferentes estruturas temporais. A reflexão-na-ação contém uma função pragmática e crítica, na medida em que é acionada por um problema a ser resolvido, exigindo ajustes e avaliações dos resultados proporcionados. Em outras palavras, pode-se argumentar que a reflexão-na-ação contém pensamentos e ações em uma dada situação de prática que não pode ser interrompida frente aos eventuais problemas surgidos. Os pensamentos reflexivos são gerados pelo self e projetados aos instantes dinâmicos da prática. As soluções dos problemas são circunstanciais, uma vez que são limitadas pelo espaço de manobra temporal que cada atividade prática permite. Por exemplo, um motorista no trânsito tem de agir frente a essa situação através de seu conhecimento-na-ação daquele contexto. Seu poder de reflexão-na-ação vai ser diferenciado em função de seu nível de habilidade como motorista, assim como seu conhecimento da cidade na qual está dirigindo. Um instrumentista, em uma situação de performance, vai precisar saber lidar (refletir-na-ação) com a situação. Tal poder de reflexão-naação vai ser dependente de seu potencial de solução de problemas acumulados e sistematizados. Assim, nesse contexto também, tem-se um agente refletindo na ação, em conjunção com seu conhecimento-na-ação. Na reflexão-sobre-a-ação (Schön, 1983), realiza-se uma retrospectiva daquilo que ocorreu, possibilitando uma avaliação da situação, "tornando explícita a estrutura de significados da experiência vivenciada" (Van Mannen, 1990, p. 77). Para Van Mannen, reflexão é uma forma de lembrança e ponderação, uma vez que envolve pensamentos sobre ações e pensamentos anteriormente experienciados. Para outros teóricos, as estruturas temporais da prática envolvem: "reflexão na e sobre a ação" (Zeichner; Liston, 1996) ou "reflexão para a ação" (Norlander-Case et al., 1999).

Burnard (2006) considera ainda os termos auto-reflexão analítica e reflexão normativa. Auto-reflexão analítica diz respeito à compreensão categorial das experiências passadas, podendo acionar uma postura crítica e de 
autoconhecimento de forças e deficiências frente às situações vivenciadas. Reflexão normativa refere-se à conscientização sobre a relação entre o conhecimento pessoal e o conhecimento sistematizado e validado por uma determinada área.

Sob a perspectiva da filosofia praxial $^{2}$ em música, Elliot (1995) argumenta que a essência do conhecimento procedimental não está na repetição dos movimentos, nem na memorização de conceitos verbais, mas na ação de aprender a refletir sobre as causas dos sucessos e falhas do curso das próprias ações. Elliot, fundamentando-se no conceito de reflexão-na-ação e conhecimentona-ação de Schön, considera que o conhecimento procedimental é não-verbal, essencialmente crítico e que atua na situação de performance musical, onde pensamento-em-ação ${ }^{3}$ está conectado com tradições, princípios, padrões e objetivos musicais focados nas situações de prática. Elliot introduz ainda, no conhecimento denominado supervisor, ${ }^{4}$ o termo imaginação-em-ação como um componente essencial do fazer musical, para referir-se ao processo prático de elaborar imagens musicais em situações de atividades musicais que, no contexto do presente artigo, é entendido como prática instrumental.

\footnotetext{
2 Elliot (1995) propõe uma substituição da filosofia estética (focada na apreciação musical) pela filosofia praxial (focada na performance) para a Educação Musical. Para esse autor, cada estilo de música corresponde a um determinado grupo de pessoas ("práticas") no sentido de uma comunidade sócio-cultural, que fazem e escutam suas músicas de acordo com suas próprias preferências. Uma discussão mais aprofundada pode ser encontrada em Westlund (2003), Goble (2003) e Regelski (2005).

3 Para Elliot, pensamento equivale a conhecimento. Portanto, pensamento-em-ação corresponde ao conhecimento-em-ação de Schön.

${ }^{4}$ Para Elliot, o conhecimento musical é intrinsecamente procedimental e multidimensional, e por isso mesmo, compreende a relação entre 4 outras formas de conhecimento, a saber: conhecimento formal, informal, impressionista e supervisor. O conhecimento supervisor está relacionado à capacidade de monitorar, administrar, ajustar e regular pensamentos próprios, tanto na ação, como no aprimoramento do músico no decorrer do tempo. Em sentido amplo, o conhecimento supervisor combina julgamentos musicais pessoais, compreensão das obrigações ou mesmo éticas musicais de uma dada prática e um tipo particular de imaginação heurística, ou seja, a habilidade de projetar e sustentar imagens pertinentes no imaginário mental antes, durante, e após a própria performance musical. O processo prático de elaborar imagens musicais (ou imaginação-em-ação) é considerado por Elliot como um componente-chave do conhecimento supervisor.
} 


\section{Perspectivas reflexivas nos fatores envolvidos na prática instrumental}

Prática instrumental é uma atividade fundamental entre músicos, que pode adquirir diversas formas dependendo da natureza e do contexto da tarefa, do nível de especialização já adquirido, bem como das diferenças individuais dos instrumentistas. Pesquisas em prática instrumental têm apontado fatores de aperfeiçoamento qualitativo das condições de uma obra em preparação, tais como:

(i) concentração;

(ii) delimitação de metas exeqüíveis;

(iii) constante auto-avaliação;

(iv) estabelecimento de estratégias flexíveis;

(v) visualização de um plano global.

A concentração configura-se na literatura como um dos fatores indispensáveis para atingir a melhoria e o refinamento da preparação na prática instrumental (Williamon et al., 2002; Chaffin et al., 2002, 2003). Em pesquisa realizada por Chaffin et al. (2003), onde a preparação de uma obra por uma pianista é acompanhada ao longo de várias sessões, os autores observaram que a pianista, apesar de praticar intensamente a peça em estudo, consumia três quartos desse tempo refletindo sobre situações de performance. Em pesquisas posteriores, o consumo de tempo maior em uma dada passagem foi tomado como um indício de reflexão no qual a pianista estava buscando resoluções de problemas, o que se traduzia, por conseguinte, em um alargamento temporal (Chaffin; Logan, 2006; Chaffin et al., 2007).

A concentração pode ser relacionada com os modos de pensamento reflexivos descritos na literatura. De acordo com Chaffin et al. (2003), a pianista na pesquisa supracitada parece ora estar delimitando o foco da atenção para a identificação de problemas a serem resolvidos em situação de prática (estágio pré-reflexivo de George e Yates [2002]), ora mantendo uma conversação reflexiva 
com a situação de prática (análogo à conversação reflexiva com a situação descrita por Hentshke e Del Ben [2006], e Hilton [2006]).

Outro fator também fundamental para o avanço da preparação na prática é que as metas estabelecidas devem ser exeqüíveis. ${ }^{5}$ De acordo com a literatura, as metas estipuladas durante a prática, no caso de profissionais, estão intimamente relacionadas com a estrutura identificada na música: (i) subseções podem ser identificadas dentre a estrutura musical para resolução de problemas técnico-mecânicos (Nielsen, 1999); (ii) quanto mais complexa a obra estudada, menores são os segmentos praticados (Chaffin et al., 2002; Williamon; Valentine, 2000; Hallam, 1997; Williamon et al., 2002; e Jørgensen, 2004); (iii) à medida que a prática progride, os segmentos estudados tornam-se mais amplos, embora possa ainda persistir refinamento técnico de certas passagens ou segmentos (Chaffin et al., 2002; Jørgensen, 2004; Hallam, 2006); e (iv) estruturas hierárquicas começam a ser desenvolvidas e integradas em um todo coerente (Џørgensen, 2004; Hallam, 2006).

O estabelecimento de metas exeqüíveis exige experimentação e avaliação preliminar da situação para determinar aspectos a serem suplantados. Fundamentando-se em Chaffin et al. (2003), pode-se argumentar que, na prática de uma obra, dependendo da fase da preparação, as metas serão distintas e contemplarão intenção de realizações focadas em: dimensões básicas (reconhecimento da obra em termos de leitura instrumental, escolha de dedilhado, delimitação de dificuldades motoras, assim como da estrutura global compreendida); dimensões interpretativas (fraseado, dinâmicas, andamento global, manipulação de estruturas temporais e pedal); e dimensões de performance (assimilação de impressões de execução - performance cues - em dimensões básicas, interpretativas e expressivas).

A literatura de prática instrumental, conforme anteriormente mencionado, parece focar-se em dimensões básicas de compreensão do texto musical, uma vez que relaciona determinação de metas com compreensão e

\footnotetext{
${ }^{5}$ Vide, por exemplo, Miklazewski (1989), Drake e Palmer (2000), Chaffin et al. (2002), e McPherson e Renwick (2001).
} 
assimilação da estrutura musical global da peça em preparação. Em termos de dimensões interpretativas, o conceito de imaginação-em-ação de Elliot (1995) parece ser um componente que conecta o potencial reflexivo à geração de idéias. Segundo Lehmann et al. (2007), a imaginação na interpretação pode estar conectada ao conjunto de escolhas expressivas, locais e globais, aplicadas e elaboradas na situação de prática de uma obra em preparação. Sloboda e Lehmann (2001), por exemplo, entrevistaram 10 pianistas após a performance pública de um prelúdio de Chopin, questionando sobre suas decisões no tocante à expressão. Os resultados apontaram duas características essenciais: (i) imaginação nas situações de prática geram intenções de expressão com diferenças objetivas em cada performance, tais como o delineamento do fraseado e de articulações em conexão com intensidades sonoras específicas, por exemplo; (ii) certas modificações nas decisões interpretativas foram frutos de resoluções de problemas durante a performance e balizadas pelo impacto emocional percebido no momento da performance. Nessas duas características acima apontadas, podese subentender dois aspectos da prática reflexiva, em termos de reflexão especular e difusa, respectivamente. Em outras palavras, na primeira 122 característica, os instrumentistas durante a prática hipotetizavam imagens que almejavam realizar durante a performance (situação de pensamento reflexivo especular e de imaginação-em-ação). Na segunda característica, existe o limiar de pensamentos reflexivos nos momentos de performance, podendo configurar-se como um modo de reflexão difusa. Esse tipo de reflexão durante a performance apresenta limites muito tênues de resolução de problemas, assim como de controle e de ajuste da situação. A reflexão difusa poderia ser associada ainda àquilo que Schön (1987) denomina de reflexão-na-ação, bem como àquilo que Elliot (1995) considera como pensamento-em-ação.

Outro fator considerado nas pesquisas em prática instrumental é a postura de constante auto-avaliação frente à situação de prática instrumental (Williamon, 2004). Certos autores, como por exemplo, McPherson e Zimmerman (2002) e Lehman et al. (2007), abordam esta questão em termos de autoregulação nas situações de prática e aprendizagem instrumental, compreendendo 
estratégias de monitoramento e de gerenciamento sobre esforço despendido. Pode-se argumentar, assim, que procedimentos de auto-avaliação podem englobar perspectivas auto-reguladoras, por envolverem modos de pensamentos reflexivos, que, por sua vez, determinam decisões e redirecionamento contínuos frente às decisões de prática.

A auto-avaliação das situações de aprendizagem musical na prática consiste na reflexão sobre a pertinência das estratégias frente às metas estipuladas, visando o refinamento e aperfeiçoamento da preparação. Tal postura exerce a função diagnóstica quando esta objetiva modos de pensamentos reflexivos em termos de identificação e o reconhecimento de pontos fortes e fracos dos conhecimentos experienciados; formativa quando se propõe a acompanhar e refletir sobre as etapas significativas desenvolvidas a partir das metas estabelecidas bem como a reconhecer interações e pontos de reflexividade com terceiros; e contínua, na medida em que possibilita (re)orientar o planejamento da prática para garantir a qualidade da preparação e do processo de aquisição do conhecimento.

A flexibilidade na escolha de estratégias na prática instrumental é também considerada fundamental para o avanço dessas situações. Segundo pesquisas (vide, por exemplo, Nielsen [1999], [2004]; Rohwer [2002]), estratégias devem ser flexíveis a ponto de serem moldadas e redirecionadas conforme as necessidades da preparação. A escolha de estratégias exige um elevado nível de reflexão em termos de hipotetização e testagem de ações para avançar a preparação, configurando-se com um meio incessante de geração de idéias embasadas em princípios e procedimentos aprendidos.

Para Jørgensen (2004), estratégias de prática podem ser definidas como pensamentos e modos de agir que músicos utilizam em situações de prática com intenção de influenciar o estado afetivo ou incorporar novos conhecimentos musicais. Para esse autor, existem estratégias: (i) executivas, que constituem formas pessoais de realizar o ensaio mental e no instrumento, o estudo das partes e do todo, o ensaio do andamento da peça, a distribuição do tempo da prática e a preparação da performance pública, por exemplo; (ii) avaliativas, quando 
essas permitem o diagnóstico explícito das forças e fraquezas pessoais na preparação de uma obra musical, e compreendem: recorrer a modelos visuais e aurais (observar/escutar por meio de registro a si mesmo para detectar e corrigir os próprios erros); ${ }^{6}$ observar/escutar interpretações de profissionais para ampliar suas possibilidades interpretativas; ${ }^{7}$ e finalmente as (iii) metaestratégias que se configuram na reflexão sobre a pertinência do conjunto de estratégias escolhidas e na busca intencional da compreensão de estratégias de terceiros para enriquecer seu próprio leque de opções. Percebemos, assim, que escolhas de estratégias configuramse como modos de pensamentos essencialmente de natureza reflexiva, uma vez que se relacionam com experimentação prática (hipotetização e testagem de idéias), avaliação das estratégias escolhidas a fim de ampliar o potencial de resolução de problemas contextualizados, além de estratégias contemplando pensamentos de natureza meta-cognitiva, que se pode subentender como pensamentos voltados a compreender e a otimizar a natureza dos próprios pensamentos.

Segundo Hultberg (2008), é fundamental se ter uma consciência de preferências individuais no estabelecimento de modos de realização na prática, uma vez que estudantes parecem escolher estratégias e preferências na prática de acordo com hábitos de aprendizagem e adaptação a modos de ensino. Em sua pesquisa, com dois instrumentistas preparando um repertório em duo, ele observou que esses estudantes praticaram preferencialmente a obra pelo treinamento exaustivo como um todo para apreender o caráter da música, para só então começar a resolver problemas à medida que esses iam surgindo. Segundo Hallam (1997), a prática exaustiva, por correção de parâmetros isolados, é um tipo de prática de iniciantes. Entretanto, não se pode descartar,

\footnotetext{
${ }^{6}$ Segundo Jørgensen (2004), o violoncelista alemão Gerhard Mantel, relata que procura estar atento a diferentes aspectos da peça enquanto a prática (ou seja, ir mudando o foco de atenção durante as situações de prática). Para esse intérprete, essa estratégia ajuda a concentrar-se e a detectar erros (p. 96).

${ }^{7}$ Santos (2007) descreve a estratégia de observação da performance de profissionais (registros comerciais em DVD) por um graduando em Bacharelado em piano, considerando-a como uma ferramenta fundamental de aperfeiçoamento de sua prática na preparação de seu repertório.
} 
como Hultberg salienta, que esse procedimento também possa estar relacionado com estilos de aprendizagem diferenciados, que precisam ser considerados.

A visualização do plano global vem sendo discutida por Chaffin e colaboradores (Chaffin et al., 2002, 2003) como um fator de aperfeiçoamento das situações de prática frente a uma obra em preparação. Esse aspecto dispõe de uma dimensão intrinsecamente reflexiva, mas pode atuar tanto num plano idealizado, como aquele exeqüível. A hipótese do plano global pode limitar-se a dimensões motoras e técnicas no aperfeiçoamento da peça como um todo. Nielsen (1997) demonstra que estudantes permanecem extremamente limitados nas questões de ordem técnica na preparação de uma obra. Por outro lado, o plano de exeqüibilidade pode funcionar como uma idealização ou imaginação especular: imaginar o que potencialmente poderia ser gerado ou atingido, mas que por sua vez necessita de alto grau de auto-avaliação e redirecionamento constante das metas e das estratégias escolhidas, integrando assim, vários dos fatores anteriormente apontados. Em uma perspectiva de reflexão contextualizada, a idealização de um plano global, quando direcionada para aquilo que possa ser realizado de forma efetiva e artística, pode ser um fator que favoreça o autoconhecimento dos pontos fortes e fracos dos conhecimentos experienciados (Jonassen et al., 1999).

\section{Considerações Finais}

A partir dos conceitos de reflexão, reflexividade e prática reflexiva, podem-se identificar alguns modos de pensamentos reflexivos, a saber:

(i) experimentação da situação (Schön, 1987), como um modo de reflexão especular (Biggs, 1999);

(ii) experimentação dos fenômenos através de estruturas temporais distintas: estágios reflexivos (George; Yates, 2002);

(iii) ceticismo reflexivo: desconfiança e auto-avaliação dos procedimentos, princípios e meios empregados para a situação 
(Mc Peck, 1981), bem como avaliação de nossas crenças, afirmações e hipóteses (Burnad, 2006);

(iv) reflexão-sobre-a-ação (Schön, 1987), como modo de (auto-) avaliação dos pontos fortes e fracos dos conhecimentos experienciados (ver por exemplo Jonassen et al., 1999);

(v) pensamento-em-ação e imaginação-em-ação (Elliot, 1995)

(vi) abertura à reflexividade (Darling, 1998) ou à reflexão difusa, que se configura como modos de pensamento convergentes e divergentes, possibilitados graças a interações intersubjetivas.

Dentre essas seis características da prática reflexiva, um modo de pensamento reflexivo que não foi contemplado nas pesquisas em prática instrumental constitui-se a abertura para a reflexividade, ou seja, a reflexão fomentada por meio de interações intersubjetivas. Fatores como a concentração e o estabelecimento de metas estão conectados com modos de pensamento reflexivo que envolvem experimentação da situação e sua abertura para os fenômenos vivenciados através de estruturas temporais em aprofundamentos distintos. A perspectiva temporal de modos de pensamento reflexivo compreende 126 o estabelecimento de metas flexíveis, ora focadas em dimensões básicas, ora em dimensões interpretativas ou de performance. Esse deslocamento do foco de atenção para resolução de problemas locais e globais são alavancados graças ao estabelecimento de metas flexíveis, sustentadas por pensamento-em-ação e imaginação-em-ação.

A postura de constante auto-avaliação nas situações de prática instrumental exige ceticismo reflexivo, tanto para a auto-avaliação dos procedimentos, princípios e meios empregados, como para conscientização de nossas crenças, afirmações e hipóteses. Auto-avaliação na prática instrumental engloba também reflexão-sobreação, assim como constatação de pontos fortes e fracos experienciados.

Prática reflexiva, embora venha sendo abordada e discutida na literatura há longo tempo, continua sendo uma temática que desperta ainda interesse e curiosidade nas mais diversas áreas, principalmente no que tange a uma abordagem reflexiva do ponto de vista educacional, frente às situações de aprendizagem em 
uma dada área de formação profissional. Por isso mesmo, a relação de modos de pensamentos reflexivos na prática instrumental surge como uma perspectiva potencial a ser fomentada no ensino e na aprendizagem no instrumento. Conforme Elliot apontou, a essência do conhecimento procedimental reside na ação de refletir sobre as experiências vivenciadas, em conexão com tradições, princípios, padrões e objetivos musicais focados nas situações de prática.

\section{Referências}

AMABILE, T. M. Creativity in context: Update to "The social psychology of creativity". Boulder: Westview, 1996.

ANDERSON, N.; FULLER, R.; DUDLEY, N. 'Rules of thumb' or reflective practice? Understanding senior phusician's decision-making about anti-thrombotic usage in atrial fibrillation. OJM-AN international journal of medicine, v. 100, n. 5, p. 263269, 2007.

BARONI, M. Hearing musical style: Cognitive and creative problems. In: DELIÈGE I.; WIGGINS, G. A. (Eds.). Musical Creativity. Multidisciplinary research in Theory and Practice. New York: Psychology Press, 1996. p. 78-93.

BIGGS J. Teaching for quality learning at university. Buckingham: Open University Press, 1999.

BROOKFIELD, S. Becoming a critically reflective teacher. San Francisco: Jossey-Bass, 1995.

BURNARD P. Rethinking the imperatives for reflective practices in arts education. In: BURNARD, P.; HENESSY S. (Eds.). Reflective practice in Arts Education. Dordrecht: Springer, 2006. p. 3-12.

CHAFFIN, R.; IMREH, G.; CRAWFORD, M. Practicing perfection: Memory and piano performance. Mahwah: Erlbaum, 2002.

CHAFFIN, R.; IMREH, G.; LEMIEUX, A. F.; CHEN, C. "It is different each time I play": variability in highly prepared musical performance. Music Perception, v. 24, p. 455-472, 2007.

. "Seeing the big picture": Piano practice as expert problem solving. Music Perception, v. 20, p. 465-490, 2003.

CHAFFIN, R.; LOGAN, T. Practicing perfection: How concert soloists prepare for performance. Advances in cognitive psychology, v. 2, n. 2-3, p. 113-130, 2006.

COLLINS, D. Real-time tracking of the creative music composition process. Digital creativity, v. 18, n. 4, p. 239-256, 2007.

COON, D. Introduction of psychology, exploration and application. St Paul: West Publishing Co., 1989. 
CRONIN, M.; CONNOLLY, C. Exploring the use of experiential learning workshops and reflective practice within professional practice development for post-graduate health promotion students. Health education journal, v. 66, n. 3, p. 286-303, 2007.

DARLING, I. Action evaluation and action theory: An assessment of the process and its connection to conflict resolution. Anais da conferência The reflective practitioner dedicated to Donald Schön.

Disponível em: <http://www.lupinworks.com/ar/Papers.html>. Acessado em: 15 de julho de 2008.

DEWEY, J. Logic: The theory of inquiry. New York: Holt, Rinehart \& Winston, 1938.

DRAKE, C.; PALMER, C. Skill acquisition in music performance. Cognition, v. 72, p. 1-33, 2000.

ELLIOT, D. J. Music matters. A new philosophy of music education. New York: Oxford University Press, 1995.

GEORGE, K.; YATES, C. Creating a CA programme in the arts: the Wigan LEA arts project. In: SHAYER, M; ADEY, P. (Eds.). Learning intelligence: Cognitive acceleration across the curriculum from 5 to 15 years. Buckingham: Open University Press, 2002. p. 85-102.

GOBLE, J. S. Perspectives on practice. Philosophy of music education review, v. $11, \mathrm{n} .1$, p. 23-44, 2003.

HALLAM, S. What do you know about practising? Toward a model synthesising the research literature. In: JØRGENSEN, H.; LEHMANN, A. C. (Eds.). Does practice make perfect?. Oslo: Norges musikkhøgskole, 1997. p. 179-231.

HALLAM. S. Music psychology in education. London: Institute of Education, 2006.

HENTSCHKE, L.; DEL BEN, L. Teaching arts as reflective practice. In: BURNARD, P.; HENESSY S. (Eds.). Reflective practice in Arts Education. Dordrecht: Springer, 2006. p. 45-54.

HILTON, M. Reflective creativity: Reforming the arts curriculum for the information age. In: BURNARD, P.; HENESSY S. (Eds.). Reflective practice in Arts Education. Dordrecht: Springer, 2006. p. 33-43.

HUGHES, M.; HEYCOX, K. Using observation for reflective practice with older people. Educational gerontology, v. 34, n. 3, p. 185-205, 2008.

HULTBERG, C. Instrumental students'strategies for finding interpretations: complexity and individual variety. Psychology of music, v. 36, n. 1, p. 7-23, 2008.

JACOB, E. Reflective practice and anthropology in culturally diverse classrooms. Elementary school journal, v. 95, n. 5, p. 451-463, 1995.

JONASSEN, D. H.; TESSNER, M.; HANNUM, W. H. Task analysis methods for instructional design. Mahwah: Lawrance Erlbaum Associates, 1999.

JØRGENSEN, H. Strategies for individual practice. In: WILLIAMON, A. (Ed.). Musical Excellence. Strategies and techniques to enhance performance. Oxford: University Press, 2004. p. 85-103. 
KULLMAN, J. Mentoring and the development of reflective practice: Concepts and context. System, v. 24, n. 4, p. 471-484, 1998.

LEE, Y.W. Crafting rules: Context-reflective data quality problem solving. Journal of management information systems, v. 20, n. 3, p. 93-119, 2003.

LEHMANN. A. C.; SLOBODA, J. A.; WOODY, R. H. Psychology for musicians. Understanding and acquiring the skills. New York: Oxford University Press, 2007.

MAMEDE, S.; SCHMIDT, H. G.; PENAFORTE, J. C. Effects of reflective practice on the accuracy of medical diagnoses. Medical education, v. 42, n. 5, p. 468-475, 2008.

MCADAMS, S. Problem-solving strategies in music composition: A case study. Music perception, v. 21, n. 3, p. 391-429, 2004.

MCPECK, J. E. Critical thinking and education. New York: St. Martin's Press, 1981.

MCPHERSON, G. E.;RENWICK, J. M. A longitudinal study of self-regulation in children's musical practice. Music Education Research, v. 3, n. 2, p. 169-186, 2001.

MCPHERSON, G. E.; ZIMMERMAN, B. J. Self-regulation of musical learning. A social cognitive perspective. In: COLWELL, R.; RICHARDSON, C. The new handbook of research on music teaching and learning. Oxford: University Press, 2002. p. 327-347.

MISHNA, F.; BOGO, M. Reflective practice in contemporary social work classrooms. Journal of social work education, v. 43, n. 3, p. 529-541.

MIKLASZEWSKI, K. A case study of a pianist preparing a musical performance. Psychology of music, v. 17, p. 95-109, 1989.

NIELSEN, S. G. Learning strategies in instrumental music practice. British Journal of Music Education, v. 16, p. 275-291, 1999.

NORLANDER-CASE, K; REAGAN, T.; CASE, C. The professional teacher: The preparation and nurturance of the reflective practitioner. San Francisco: Jossey-Bass, 1999.

OTACIOGLU, S. G. The comparison of problem solving skills of post-graduate students in teacher's college in terms of their levels. EGITIM - Arastirmalari-Eurasian journal of educational research, v. 7, n. 29, p. 73-83, 2007.

REGELSKI, T. A. Curriculum: Implications of aesthetic versus praxial philosophers. In: ELLIOT, D. J. (Ed.). Praxial music education. Oxford: University Press, 2005. p. 219-248.

REID, A.; PETOCZ, P. Learning domains and the process of creativity. Australian educational researcher, v. 31, n. 2, p. 45-62, 2004.

REYNOLDS, A. M.; BEITLER, N. S. A reflective pratice in a middle-school instrumental setting. Bulletin of the council for research in music education, n. 173, p. 55-69, 2007.

REYNOLDS, A. M.; JEROME, A.; PRESTON, A. L.; HAYNES, H. Service-teaching in music education: Participants reflections. Bulletin of the council for research in music education, n. 165, p. 79-91, 2006.

ROHWER, D. Understanding practice: An investigation and applications. International Journal of Music Education, v. 40, n. 1, p. 15-25, 2002. 
RUCH, G. Reflective practice in contemporary child-care social work: The role of containment. British journal of social work, v. 37, n. 4, p. 659-680, 2007.

SANTOS, R. A. T. dos. Mobilização de conhecimentos musicais na preparação do repertório pianístico ao longo da formação acadêmica: três estudos de caso. Tese de doutorado, Música - Porto Alegre: UFRGS, 2007.

SCHÖN, D. Educating the reflective practitioner. São Francisco: Jossey Bass, 1987.

The reflective practitioner: How professionals think in action. New York: Basic books, 1983.

SLOBODA, J. A.; LEHMANN, A. C. Performance correlates of perceived emotionality in different interpretations of a Chopin Piano Prelude. Music Perception, v. 19, n. 1 , p. 87-120, 2001.

SMALL, M. W.; CULLEN J. L. Socialization of business practitioners - learning to reflect on current business practices. Journal of business ethics, v. 14, n. 8, p. 695-701, 1995.

SMITH, P. A. C. Action learning and reflective practice in project environment that are related to leadership development. Management learning, v. 32, n. 1, p. 31-48, 2001.

TAN, C. Improving schools through reflection for teacher's: lessons from Singapore. School effectiveness and school improvement, v. 19, n. 2, p. 225-238, 2008.

TOWNDROW, P. A. Critical reflective practice as a pivot in transforming science education. A report of teacher-researcher collaborative interaction in response to assessment reforms. International journal of science education, v. 30, n. 7, p. 903-922, 2008.

VAN MANNEN, M. Researching lived experience: Human science for an action sensitive pedagogy. State Canada: Althouse, 1990.

WESTLUND, H. Reconsidering aesthetic experience in praxial music education. Philosophy of music education review, v. 11, n. 1, p. 45-62, 2003.

WIGGINS, J. H. The nature of shared musical understanding and its role in empowering independent musical thinking. Bulletin of the council for research in music education, n. 143, p. 65-90, 1999.

WILLIAMON, A. Musical Excellence. Strategies and techniques to enhance performance. Oxford: University Press, 2004.

WILLIAMON, A.; VALENTINE E. Quantity and quality of musical practice as predictors of performance quality. British journal of psychology, v. 91, p. 353-376, 2000.

WILLIAMON, A.; VALENTINE E; VALENTINE, J. Shifting the focus of attention between levels of musical structure. European journal of cognitive psychology, v. 14, p. 492-520, 2002.

ZEICHNER, K; LISTON, D. Reflective thinking: An introduction. Mahwah: Lawrance Erlsbaum Associates, 1996.

Regina Antunes Teixeira dos Santos: jhsreg@adufrgs.ufrgs.br

Recebido e aprovado em 04 de agosto de 2008 